\title{
Metallacarborane-Based Metal-Organic Framework with a Complex Topology
}

Robert D. Kennedy, ${ }^{\dagger}$ Daniel J. Clingerman, ${ }^{\dagger}$ William Morris, $^{\dagger}$ Christopher E. Wilmer, $^{\dagger}$, Il Amy A. Sarjeant, ${ }^{\dagger}$ Charlotte L. Stern, ${ }^{\dagger}$ Michael O’Keeffe, ${ }^{\S}$ Randall Q. Snurr, ${ }^{\dagger}$ Joseph T. Hupp, $^{\dagger}$ Omar K. Farha, ${ }^{\dagger, \nabla}$ and Chad A. Mirkin* ${ }^{\dagger}$

${ }^{\dagger}$ Department of Chemistry and International Institute for Nanotechnology, and ${ }^{\ddagger}$ Department of Chemical \& Biological Engineering, Northwestern University, 2145 Sheridan Road, Evanston, Illinois 60208, United States

${ }^{\S}$ Department of Chemistry, Arizona State University, Tempe, Arizona 85287, United States

${ }^{\nabla}$ Department of Chemistry, Faculty of Science, King Abdulaziz University, Jeddah 22254, Saudi Arabia

\section{Supporting Information}

ABSTRACT: The long, linear cobalt(III) bis(dicarbollide)based bis(isophthalic acid) anion was synthesized as a tetraphenylphosphonium salt in five steps from 8-iodo-closo1,2- $\mathrm{C}_{2} \mathrm{~B}_{10} \mathrm{H}_{11}$. The solvothermal reaction between the anionic bis(isophthalic acid) linker and copper(II) nitrate in acidified DMF yielded single crystals. Despite the tendency for copper(II) and analogous linear tetraacids to form members of an isoreticular family of metal-organic frameworks (MOFs) with the fof topology, single-crystal X-ray diffraction analysis revealed the growth of three different frameworks. These MOFs, NU-150, NU-151, and NU-152, have three distinct topologies: fof, sty, and hbk, respectively. NU-152 has a novel quadrinodal topology in which cuboctahedral coordination polyhedra are each connected to 10 neighboring polyhedra via the cobalt bis(dicarbollide) portions of the linkers. The formation of these frameworks illustrates the limitations of structure prediction in MOF chemistry and the possibility of using flexible linkers to generate unexpected topologies. Furthermore, this work represents the first example of the incorporation of an anionic bis(dicarbollide) unit into a MOF.

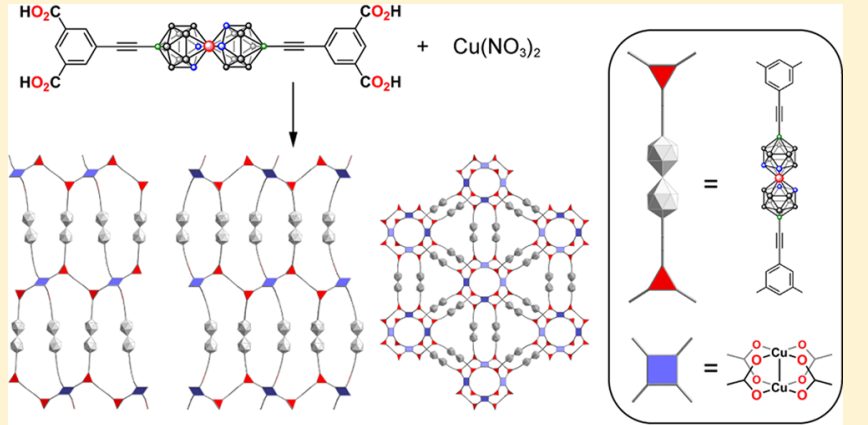

NU-150 NU-151 NU-152

\section{INTRODUCTION}

Porous coordination polymers ${ }^{1-4}$ constitute a class of materials with potential in the areas of ion exchange, ${ }^{5,6}$ catalysis, ${ }^{7,8}$ gas separation, ${ }^{9-12}$ sensing, ${ }^{13}$ and storage. ${ }^{14-16}$ Crystalline porous coordination polymers, commonly known as metal-organic frameworks (MOFs), are unique as their properties can be precisely tailored through judicious choice of ligand and metal combination. The underlying topologies of MOFs are particularly important as they define the properties of the material. ${ }^{17}$ Topology is dictated by the geometries of the structural components of the MOF, which are typically polytopic organic ligands and metal clusters with defined geometries, herein referred to as "linkers" and "nodes", respectively. Often, the relationships between the structural components are well-defined, which allows for structure prediction and the targeting of specific MOFs with desirable properties. This implementation of rational design is a particularly attractive aspect of MOF chemistry. ${ }^{18}$ Much attention has been focused on the investigation of isoreticular frameworks, ${ }^{19}$ i.e., families of MOFs with the same underlying topology, as they provide a unique opportunity to investigate structure-activity relationships in a systematic fashion. ${ }^{20}$ \section{(1)}




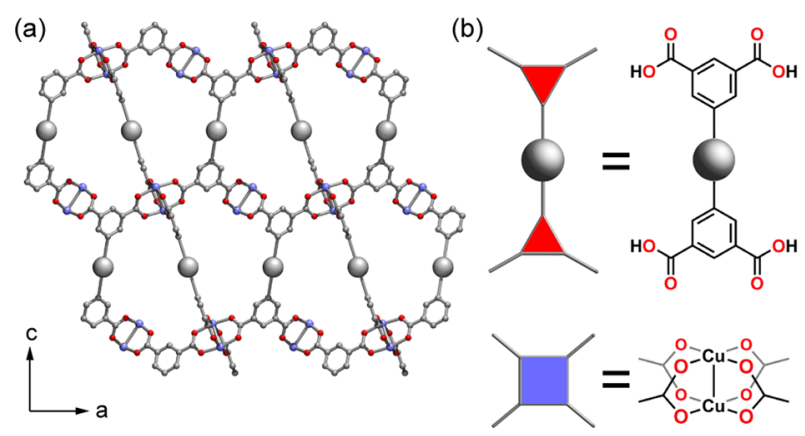

(c)
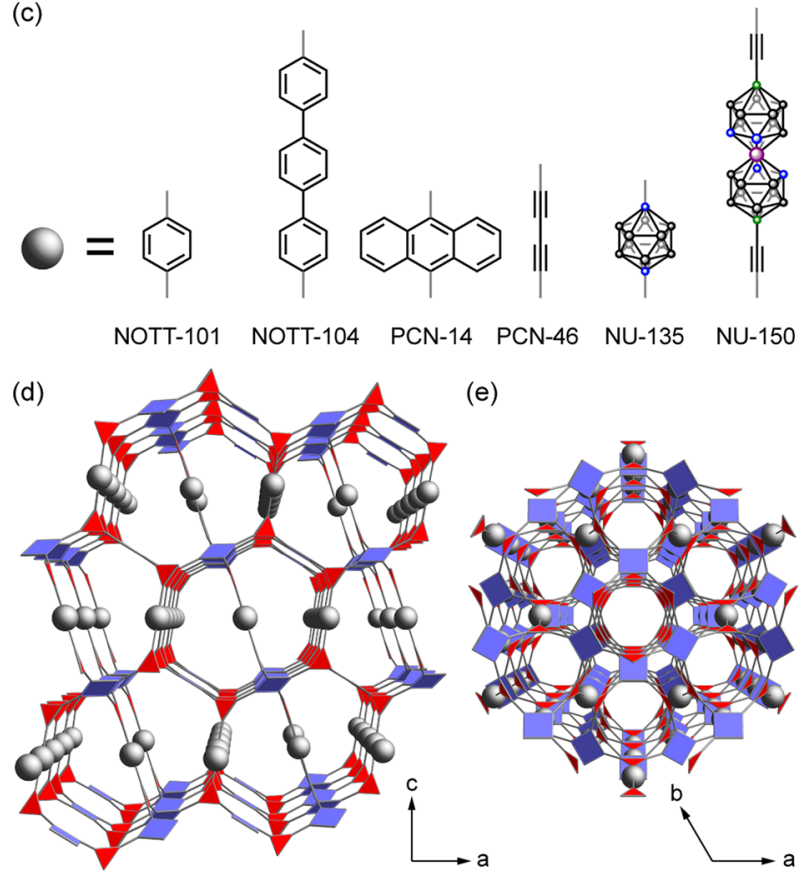

Figure 1. Structure of isoreticular MOFs with the fof topology. ${ }^{22}$ (a) Generalized structure viewed along the crystallographic $a$ axis. Atom color code: $\mathrm{C}=$ small gray spheres; $\mathrm{O}=$ red; $\mathrm{Cu}=$ blue. The spacer subunit between the isophthalate groups is represented by a large gray sphere. (b) Simplified representations of the generalized tetraacid linker and biscopper(II) paddlewheel nodes. The tetraacid linker is composed of two three-coordinate (3-c) vertices, which are represented by red triangles, connected via the spacer group (gray spheres). (c) Several examples of organic and inorganic spacer unit. (d, e) Simplified extended structure, illustrating the topology of the framework.

bis(isophthalic acid) linkers that have been used in combination with biscopper(II) paddlewheels, 18 produce MOFs with the fof topology. . $^{25-35}$ The remaining two linkers, which are based on the naphth-1,4-diyl subunit ${ }^{20}$ or a porphyrin, ${ }^{36}$ produce MOFs that crystallize in tetragonal space groups with the stx and lvt topologies, respectively. In these cases, the steric bulk of the cores of the linkers renders the fof topology unfeasible. In a related example, a fluorene-based ligand with a slight curvature produced a MOF with the rare sty topology. ${ }^{37}$ Interestingly, it is not possible to generate the sty topology with rigid, linear linkers because of the orientation of opposing biscopper(II) paddlewheels (vide infra).

As a part of our research into the synthesis and properties of carborane-based MOFs, ${ }^{11,12,24,38-40}$ we have been investigating a series of axially functionalized bis(dicarbollide) metal complexes $^{41}$ as linkers. Bis(dicarbollide) complexes are attractive because they combine rich redox chemistry, ${ }^{42,43}$ comparable to that of cyclopentadienyl complexes, with a linear geometry that is perfectly suited to the construction of extended materials. MOFs that are based on these metallacarboranes are particularly interesting as they show potential in the area of stimuli responsive porous materials for gas storage and separation, sensing, and waste remediation applications. We were targeting a MOF with both high porosity and high phase purity, and thus prepared an anionic cobalt bis(dicarbollide) complex that is functionalized in the axial positions with 5-ethynylisophthalic acid groups $[5]^{-}$ (Scheme 1). This linker was chosen specifically because of the above-mentioned propensity of analogous tetraacids to form, reliably and in high purity, highly porous MOFs with the

Scheme 1. (A) Synthesis of Linker $\left[\mathrm{PPh}_{4}\right][5] .^{a}$ (B) ORTEPType Representation of the Crystallographically Determined Molecular Structure of the $[5]^{-}$Anion in Its Cesium Salt ${ }^{b}$

(a)
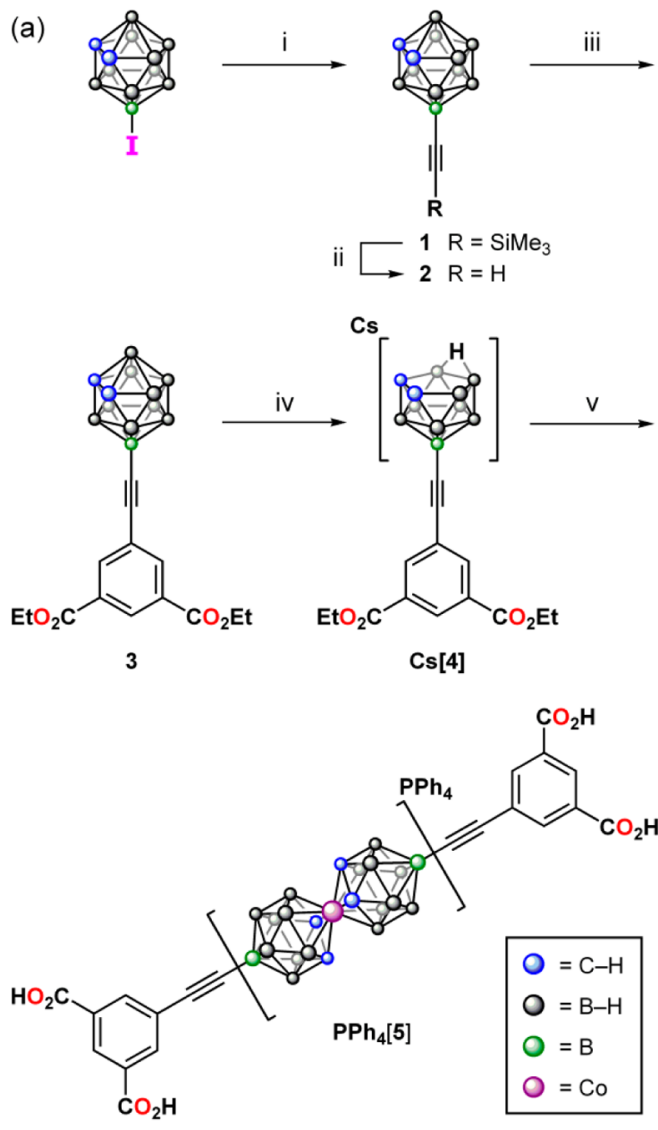

(b)

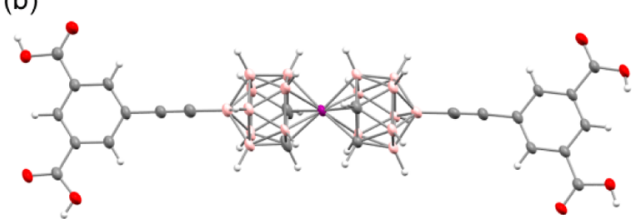

${ }^{a}$ Reagents and conditions: (i) (trimethylsilyl)ethynylmagnesium bromide (3 equiv), $\mathrm{PdCl}_{2}\left(\mathrm{PPh}_{3}\right)_{2}(5 \mathrm{~mol} \%)$, THF $/ \mathrm{Et}_{2} \mathrm{O}, 65{ }^{\circ} \mathrm{C}, 16$ h, $92 \%$. (ii) $\mathrm{KOH}$ (2 equiv), $\mathrm{H}_{2} \mathrm{O} / \mathrm{MeOH}(1: 4), \mathrm{rt}, 2$ h, 96\%. (iii) diethyl 5-iodoisophthalate, $\mathrm{Pd}\left(\mathrm{PPh}_{3}\right)_{4}(3 \mathrm{~mol} \%), \mathrm{CuI}(10 \mathrm{~mol} \%)$, $i$ $\mathrm{Pr}_{2} \mathrm{NEt} / \mathrm{THF}$ (1:1), $65{ }^{\circ} \mathrm{C}, 24 \mathrm{~h}, 85 \%$. (iv) CsF, EtOH, reflux, $6 \mathrm{~h}$, 95\%. (v) $\mathrm{CoCl}_{2}, \mathrm{NaOH}$ (40\% aq), $105{ }^{\circ} \mathrm{C}, 1 \mathrm{~h} ; \mathrm{Et}_{2} \mathrm{O}, \mathrm{HCl}$ (aq); $\left[\mathrm{PPh}_{4}\right] \mathrm{Br}, \mathrm{H}_{2} \mathrm{O}$. ${ }^{b}$ Thermal ellipsoids are drawn at $50 \%$ probability. Atom color code: $\mathrm{Co}=$ purple; $\mathrm{C}=$ gray; $\mathrm{H}=$ white; $\mathrm{B}=$ pink; $\mathrm{O}=$ red. Cesium cations are omitted for clarity. 

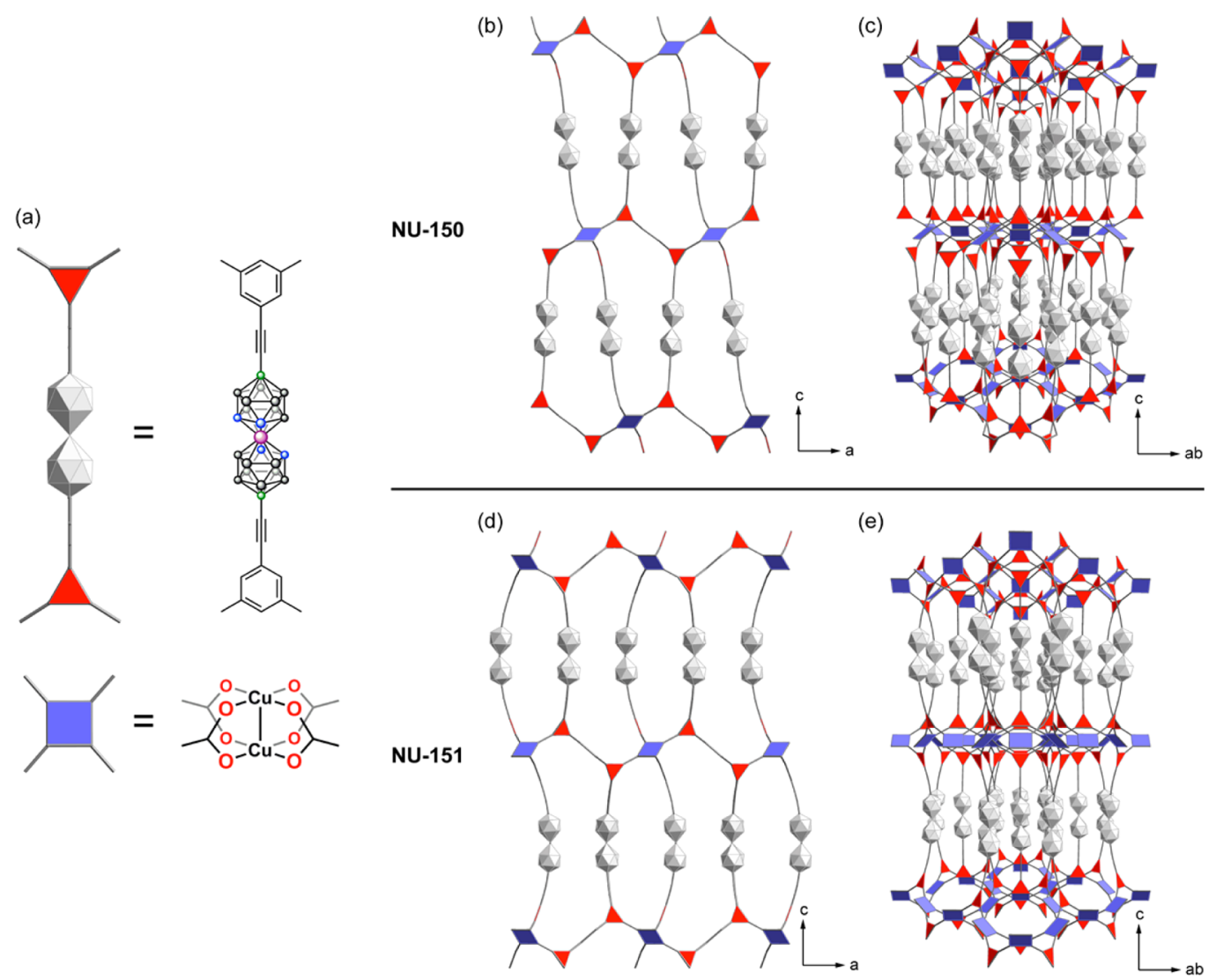

Figure 2. Representation of the crystal structures of NU-150 and NU-151. (a) Simplified representations of the linker (top) and biscopper(II) paddlewheel node (bottom). The bis(dicarbollide) linker is defined as being composed of two three-coordinate (3-c) vertices mutually connected through the cobalt bis(dicarbollide) moiety. These are represented by two red triangles connected by two conjoined gray icosahedra. This description is particularly suitable for this system because of the lateral and torsional flexibility of the bis(dicarbollide) linker. (b, c) Orthographic and perspective views, respectively, of NU-150. (d, e) Orthographic and perspective views, respectively, of NU-151. In projections b and d, some red triangles and blue squares are not visible as they are oriented parallel to the viewing direction. In all cases, the anionic nature of the bis(dicarbollide) complex leads to a framework with an overall negative charge. Although countercations are necessarily present, ${ }^{46}$ they could not be located crystallographically, and the solvent-occupied regions were treated with a solvent-masking procedure during refinement. ${ }^{47}$

fof topology. Interestingly, the solvothermal reaction between $\left[\mathrm{PPh}_{4}\right][5]$ and $\mathrm{Cu}\left(\mathrm{NO}_{3}\right)_{2} \cdot 2.5 \mathrm{H}_{2} \mathrm{O}$ in acidified DMF resulted in a mixture of MOFs with three distinct topologies: (1) NU-150, which has the expected fof topology; (2) NU-151, which has the rare sty topology; (3) NU-152, which has an unprecedented hbk topology and consists of a complex network of interconnected metal-organic polyhedra. The formation of these unexpected topologies is ascribed to the length (ca. $22 \AA$ ) and flexibility of the linker. The synthesis and characterization of these unique and potentially useful frameworks is described herein.

\section{RESULTS AND DISCUSSION}

The anionic linker $[\mathbf{5}]^{-}$was synthesized in five steps from 8-Icloso-1,2- $\mathrm{C}_{2} \mathrm{~B}_{10} \mathrm{H}_{11}$ (Scheme 1). ${ }^{41}$ Detailed experimental procedures are presented in the Supporting Information. Briefly, the trimethylsilylethynyl group was installed at the 8position of the carborane cage via a palladium-mediated Kumada coupling reaction. ${ }^{44}$ Following the removal of the trimethylsilyl group to give the terminal alkyne 2, the diethyl isophthalate group was attached using typical Sonagashira conditions to give compound 3 . The structures of compounds 2 and 3 were confirmed via single-crystal X-ray diffraction analyses (Supporting Information). The reaction of 3 with cesium fluoride in refluxing ethanol ${ }^{45}$ resulted in the quantitative deboronation of the carborane cage to give the anionic nido-compound $[4]^{-}$as the cesium salt. Importantly, the deboronation was highly selective, and only the 1substituted nido-compound was obtained. Treatment of Cs[4] with cobaltous chloride in hot, concentrated aqueous sodium hydroxide resulted in the saponification of the esters and the simultaneous formation of the anionic cobalt(III) bis(dicarbollide) complex. ${ }^{42}$ Following acidification and extraction, the complex was isolated as the tetraphenylphosphonium salt $\left[\mathrm{PPh}_{4}\right][5]$. A single-crystal X-ray diffraction study revealed that the distance between the terminal carbons of the isophthalic acid groups is ca. $21.6 \AA$ (Scheme 1, Supporting Information). This distance is comparable to that of the analogous quinquephenyl-based ligand $(19.7 \AA)$ that is a component of NOTT-104. ${ }^{20}$

The solvothermal reaction between $\left[\mathrm{PPh}_{4}\right][5]$ and $\mathrm{Cu}$ $\left(\mathrm{NO}_{3}\right)_{2} \cdot 2.5 \mathrm{H}_{2} \mathrm{O}$ in a mixture of $\mathrm{DMF}$ and aqueous tetrafluoroboric acid at $80{ }^{\circ} \mathrm{C}$ for 3 days resulted in the growth of small, emerald green crystals. Inspection of the material using an optical microscope revealed a mixture of green hexagonal plates and prisms. In addition, a small number of crystals with cubic morphology were also present in the mixture. Singlecrystal X-ray diffraction analyses were performed on several crystals. Three structures were obtained (NU-150, NU-151, 
(a)

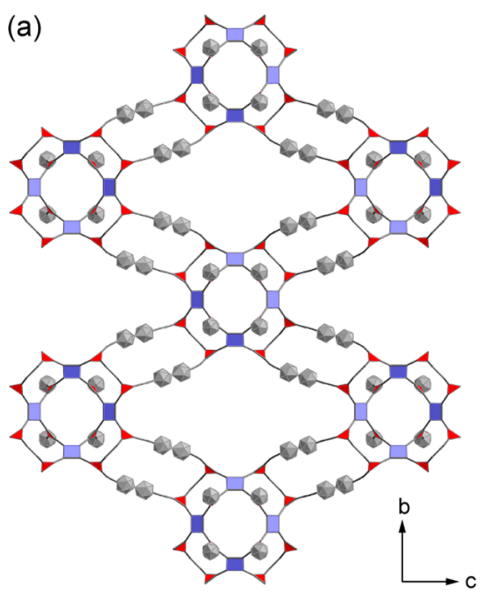

(b)

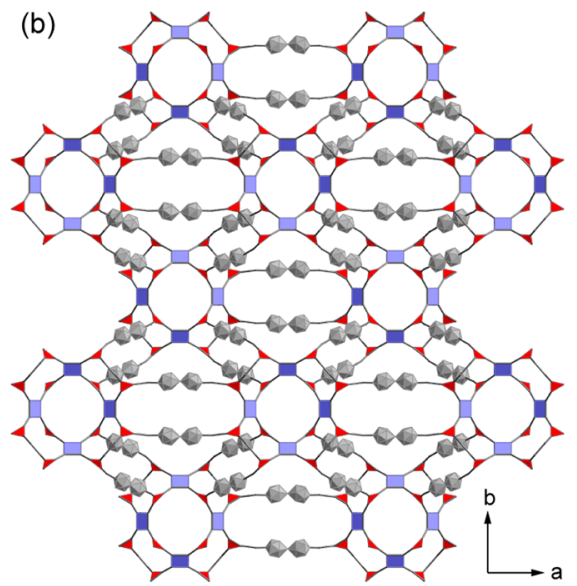

(c)

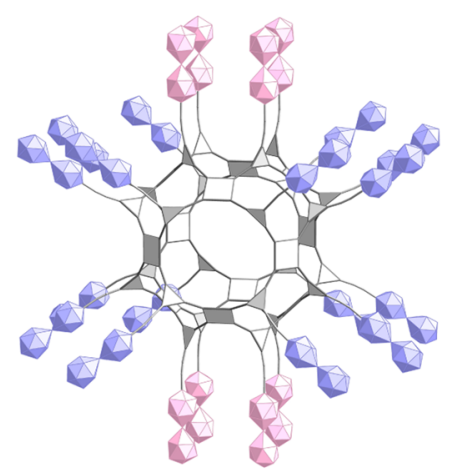

(d)

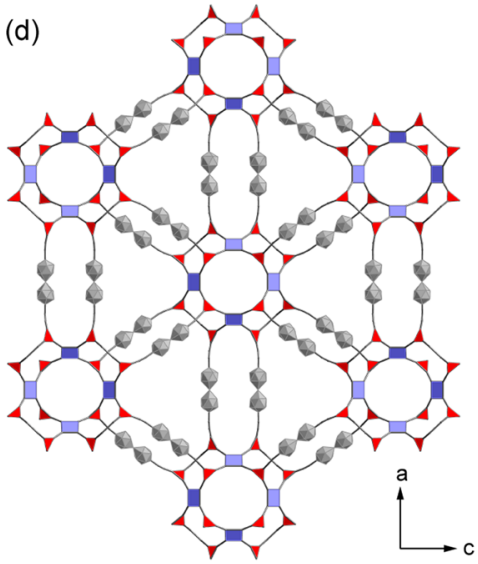

(e)

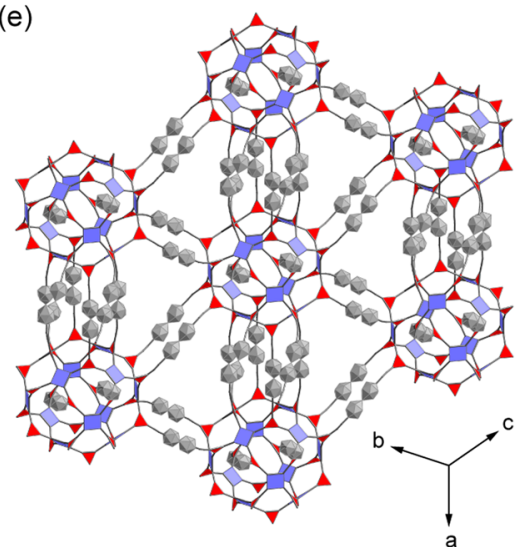

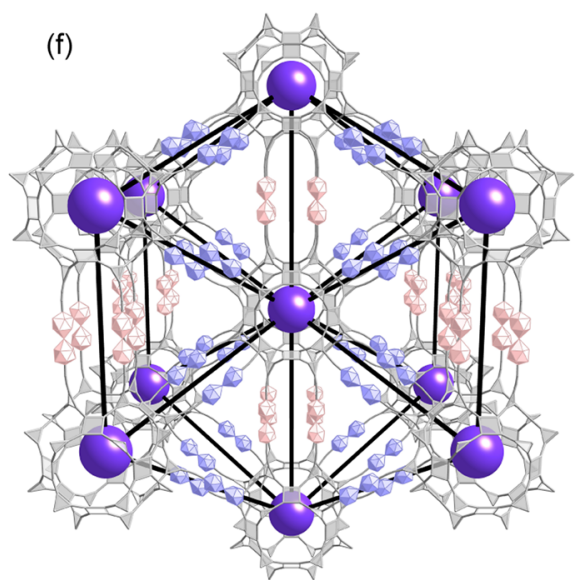

Figure 3. Representations of the crystal structure of NU-152. (a, b, d, e) The bis(dicarbollide) linkers are represented by two red triangles connected by gray conjoined icosahedra, and the biscopper(II) paddlewheels are represented by blue squares (as shown in Figure 1). (c) A single cuboctahedral supercluster (gray) with crystallographically independent linkers shown in blue and pink. (f) Purple spheres represent the centroids of the 10coordinate cuboctahedra, and black lines represent the connectivities between the cuboctahedra via sets of four "pink" linkers or sets of two "blue" linkers.

and NU-152), which all have the same general formula $\left(\mathrm{LCu}_{2}\right)$, yet each possess a different topology.

Single-crystal X-ray diffraction analysis was performed on one of the platelike crystals. Solution and refinement of the data in the space group $R 32$ (155) led to structure with the expected fof topology and unit cell dimensions of $a=b=18.1367(8) \AA$ and $c=69.883(4) \AA$; this framework is denoted as NU-150. NU-150 has a layered structure (Figure 2): the isophthalate units and biscopper(II) paddlewheels define sheetlike motifs that are aligned parallel to the crystallographic $a b$ plane. Considering the paddlewheels and the isophthalate units as vertices and edges, respectively, the $a b$ layers resemble a kagome net; i.e., the $\mathrm{Cu}$-isophthalate layers contain large hexagonal and small triangular pores. The $\mathrm{Cu}$-isophthalate layers are connected to one another by the bis(ethynyldicarbollide) portions of the linkers, which are aligned approximately parallel to the crystallographic $c$ axis. In terms of crystallographic symmetry, the layers are related to one another by a threefold screw axis that runs parallel to the $c$ axis; thus, the unit cell is composed of three $\mathrm{Cu}$-isophthalate layers, and the layers repeat along the $c$ axis in an $A B C A B C$ fashion. Interestingly, NU-150 is not interpenetrated and thus differs from the analogous, yet catenated, quinquephenyl-based MOF, NOTT-104. ${ }^{20}$ This is probably because of the steric bulk of the metallacarborane core. Thus, NU-150 possesses a relatively large solvent-accessible void space of ca. $71 \%$, as determined using PLATON. ${ }^{46,48}$

The structure of NU-151 was solved via a combined experimental and theoretical approach. It was possible to obtain a partial structure solution in the space group $P 6_{3} m c$ (186) with unit cell parameters $a=b=18.248(2) \AA$ and $c=$ 47.113(7) Å. The partial solution revealed a $\mathrm{Cu}-$ isophthalate kagome net motif, similar to that found in NU-150, and also the positions of the central cobalt atoms of the metallacarborane linkers (Figure 2). The unit cell parameters, together with the relative positions and orientations of the structural elements, suggested that NU-151 had the sty topology. Thus, the cell parameters were used to produce a structural model with the sty topology, ${ }^{49}$ the optimization of which resulted in a structure in the $P \overline{3} 1 c$ (163) space group. The experimental data were then refined successfully using this model. NU-151 shares many structural features with NU-150. NU-151 also belongs to a trigonal space group, and, as mentioned above, the structure exhibits the same $\mathrm{Cu}-$ isophthalate kagome net motif that is found in NU-150. In a similar fashion to $\mathbf{N U}-\mathbf{1 5 0}$, the $\mathrm{Cu}$-isophthalate planes are connected to one another via the metallacarborane portions of the linkers, which are aligned approximately parallel with the crystallographic $c$ axis. However, in the case of NU-151, the layers are connected in such a way that each layer is related to 
its neighbors via twofold rotation axes that are aligned perpendicular to the crystallographic $c$ axis. Thus, the unit cell is composed of two layers rather than three, and the layers repeat along the $c$ axis in an $\mathrm{ABAB}$ fashion. The linkers are each disordered over two positions with approximately 2:1 occupancy. The positions of the linkers influence the porosity of the framework: when the linkers are in the positions of major occupancy, linear channels, which are aligned parallel to the each of the cell axes, are present. When the linkers are in the positions of minor occupancy, the linear channels are obstructed. In each case, the solvent-accessible void space is ca. $70 \% .{ }^{48}$ The linkers exhibit an obvious curvature, especially when they are in the minor occupancy positions. Indeed, because of the relative angles of the opposing isophthalate groups, it is not possible for the sty topology to exist with a linear linker. From the data it is not possible to determine whether the occupancy is random or whether there is longrange order.

The structure of NU-152 was solved and refined from singlecrystal X-ray diffraction data collected from a crystal with approximately cubic morphology. NU-152 crystallizes in the orthorhombic space group Immm with unit cell parameters $a=$ 36.549(3) $\AA, b=38.148(3) \AA$, and $c=55.536(4) \AA$. In contrast to NU-150 and NU-151, the rather complex structure of NU$\mathbf{1 5 2}$ has a novel, quadrinodal hbk topology and is composed of interconnected metal-organic polyhedra (MOPs) with topological symmetry $I 4 / \mathrm{mmm}$ (Figure 3 ). These coordination polyhedra, or tertiary building units (TBUs), are composed of 12 biscopper paddlewheels and 24 isophthalate moieties that describe the vertices and edges, respectively, of a cuboctahedron, and are commonly referred to as MOP- $1 .^{50-52}$ The interconnected MOP-1 motif is relatively common among $\mathrm{Cu}-$ and $\mathrm{Zn}$-isophthalate MOFs. ${ }^{17}$ The motif is present in MOFs with exceptionally high porosities, for example, the isoreticular rht-MOF family in which the TBUs are each linked to 12 others in a face-centered cubic array. ${ }^{15,53-56}$ In the case of NU-152, the length and unusual flexibility of the linker allow for the hbk topology to occur. The TBUs are each connected via the 24 bis(dicarbollide) linkers to 10 neighboring polyhedral in a body-centered tetragonal array. Along the $a$ axis, each polyhedron is connected to two neighbors via sets of four linkers. Each polyhedron is connected to the eight remaining near-neighbors via sets of two linkers. This arrangement of linkers and nodes produces a much larger solvent-accessible void space (ca. 79\%) than is present in NU-150 or NU-151 (ca. $70 \%)$. Importantly, this arrangement differs markedly from that of the family of MOFs derived from rigid meta-phenylenebased or methylene-based linkers. ${ }^{55,57,58}$ In these cases, each MOP-1 TBU is linked to six others in a primitive cubic array.

\section{CONCLUSIONS}

An attractive aspect of MOF chemistry is that it allows for the targeted synthesis of frameworks with specific topologies. The periodic nature of MOFs makes them ideal for computational study, and, thus, a particular material with desirable properties may be designed and then synthesized. This combination of calculation with reliable, predictable syntheses is very powerful. Certain combinations of linkers and nodes are especially robust, in that they reliably produce a single topology regardless of the nature of the core of the linker. However, as this work illustrates, the expected topology is not always obtained even when a particularly robust system is used. In this work, the combination of a bis(isophthalic acid) linker and a biscopper-
(II) paddlewheel node, which ordinarily generates MOFs with the topology fof, resulted in the formation of MOFs with three different topologies. In addition to a MOF with the expected fof topology, MOFs with the unusual topologies sty and hbk were also formed. Considering the curvature of the linker exhibited by the two unusual structures, it seems that the length and flexibility of the linker play an important role in the formation of the unprecedented framework. This work exemplifies how new topologies may be accessed by using structural units that possess properties that are not usually associated with MOFs, for example, flexible or curved rather than rigid and with defined angles. Such structural units should be flexible enough to generate new topologies, yet stiff enough to generate porous structures rather than collapsed, condensed structures. Indeed, the solvent-accessible void space of NU-152, the structure of which is possible because of the flexibility of the linkers, is significantly greater than that of NU-150. As the underlying topology of a MOF has a critical influence on the material properties, strategies to produce new topologies and thus new properties are very attractive. Indeed, the expansion of the number of known topologies may greatly expand the scope of the MOF design. Furthermore, we will seek to expand the chemistry of these linkers to other metal centers. For example, it has also been shown that tetracarboxy linkers when combined with zinc paddlewheels generate novel topologies along with the standard fof topology. ${ }^{59,60}$ With this in mind we are investigating the combination of novel redox-active polytopic metallacarborane-based linkers with a variety of metal-based nodes in order to generate new families of stimuli-responsive MOFs with new properties and topologies for use in areas such as ion exchange, gas separation, and energy storage.

\section{ASSOCIATED CONTENT}

\section{S Supporting Information}

General procedures, materials, instrumentation, synthesis, and characterization of all compounds. Crystallographic information files (CIF) for compounds 2, 3, Cs $[\mathbf{5}],\left[\mathrm{PPh}_{4}\right]_{3}\left[\mathbf{5}-\mathbf{2} \mathbf{H}^{+}\right]$, NU151, and NU-152. Crystal structure and refinement details for NU-150 in CIF format. Calculated structures of NU-150 and NU-151 in CIF format. This material is available free of charge via the Internet at http://pubs.acs.org.

\section{AUTHOR INFORMATION}

\section{Corresponding Author}

*E-mail: chadnano@northwestern.edu.

\section{Present Address}

"University of Pittsburgh, Swanson School of Engineering, Department of Chemical \& Petroleum Engineering, 1249 Benedum Hall, 3700 O’Hara Street, Pittsburgh, PA 15261.

\section{Notes}

The authors declare no competing financial interest.

\section{ACKNOWLEDGMENTS}

C.A.M. acknowledges support from U.S. Army award W911NF-11-1-0229, NSF award CHE-1149314, and the NERC/EFRC DOE/Office of Science/Office of Basic Energy Sciences award DE-SC0000989. O.K.F., J.T.H., and R.Q.S. thank DOE ARPA-E and the Stanford Global Climate and Energy Project for support of work relevant to methane and $\mathrm{CO}_{2}$, respectively. C.E.W. gratefully acknowledges support from a Ryan Fellowship from the Northwestern University International Institute for Nanotechnology. Computational 
work was supported through the resources provided by Information Technology at Northwestern University as part of its shared cluster program, Quest.

\section{REFERENCES}

(1) Cook, T. R; Zheng, Y.-R.; Stang, P. J. Chem. Rev. 2013, 113, 734-777.

(2) Oh, M.; Mirkin, C. A. Nature 2005, 438, 651-654.

(3) Spokoyny, A. M.; Kim, D.; Sumrein, A.; Mirkin, C. A. Chem. Soc. Rev. 2009, 38, 1218-1227.

(4) Kitagawa, S.; Kitaura, R.; Noro, S.-i. Angew. Chem., Int. Ed. 2004, 43, 2334-2375.

(5) Min, K. S.; Suh, M. P. J. Am. Chem. Soc. 2000, 122, 6834-6840. (6) Oh, M.; Mirkin, C. A. Angew. Chem., Int. Ed. 2006, 45, 54925494.

(7) Lee, J.; Farha, O. K.; Roberts, J.; Scheidt, K. A.; Nguyen, S. T.; Hupp, J. T. Chem. Soc. Rev. 2009, 38, 1450-1459.

(8) Ma, L.; Abney, C.; Lin, W. Chem. Soc. Rev. 2009, 38, 1248-1256.

(9) Oh, M.; Stern, C. L.; Mirkin, C. A. Chem. Commun. 2004, 26842685 .

(10) Li, J.-R.; Kuppler, R. J.; Zhou, H.-C. Chem. Soc. Rev. 2009, 38, 1477-1504.

(11) Bae, Y.-S.; Farha, O. K.; Spokoyny, A. M.; Mirkin, C. A.; Hupp, J. T.; Snurr, R. Q. Chem. Commun. 2008, 4135-4137.

(12) Bae, Y.-S.; Spokoyny, A. M.; Farha, O. K.; Snurr, R. Q.; Hupp, J. T.; Mirkin, C. A. Chem. Commun. 2010, 46, 3478-3480.

(13) Kreno, L. E.; Leong, K.; Farha, O. K.; Allendorf, M.; Van Duyne, R. P.; Hupp, J. T. Chem. Rev. 2012, 112, 1105-1125.

(14) Suh, M. P.; Park, H. J.; Prasad, T. K.; Lim, D.-W. Chem. Rev. 2012, 112, 782-835.

(15) Farha, O. K.; Yazaydın, A. Ö.; Eryazici, I.; Malliakas, C. D.; Hauser, B. G.; Kanatzidis, M. G.; Nguyen, S. T.; Snurr, R. Q.; Hupp, J. T. Nature Chem. 2010, 2, 944-948.

(16) Furukawa, H.; Ko, N.; Go, Y. B.; Aratani, N.; Choi, S. B.; Choi, E.; Yazaydın, A. Ö.; Snurr, R. Q.; O’Keeffe, M.; Kim, J.; Yaghi, O. M. Science 2010, 329, 424-428.

(17) O'Keeffe, M.; Yaghi, O. M. Chem. Rev. 2012, 112, 675-702.

(18) O'Keeffe, M. Chem. Soc. Rev. 2009, 38, 1215-1217.

(19) Eddaoudi, M.; Kim, J.; Rosi, N.; Vodak, D.; Wachter, J.; O'Keeffe, M.; Yaghi, O. M. Science 2002, 295, 469-472.

(20) Lin, X.; Telepeni, I.; Blake, A. J.; Dailly, A.; Brown, C. M.; Simmons, J. M.; Zoppi, M.; Walker, G. S.; Thomas, K. M.; Mays, T. J.; Hubberstey, P.; Champness, N. R.; Schröder, M. J. Am. Chem. Soc. 2009, 131, 2159-2171.

(21) Li, H.; Eddaoudi, M.; Groy, T. L.; Yaghi, O. M. J. Am. Chem. Soc. 1998, 120, 8571-8572.

(22) In this paper, the tetratopic linker is considered as two conjoined 3-c nodes, and the corresponding $(3,4)-\mathrm{c}$ net has the symbol fof (see ref 17) The tetratopic linker can also be considered as one 4-c node, in which case the structures can be described as 4-c nets with the symbol nbo.

(23) Ma, S.; Sun, D.; Simmons, J. M.; Collier, C. D.; Yuan, D.; Zhou, H.-C. J. Am. Chem. Soc. 2007, 130, 1012-1016.

(24) Kennedy, R. D.; Krungleviciute, V.; Clingerman, D. J.; Mondloch, J. E.; Peng, Y.; Wilmer, C. E.; Sarjeant, A. A.; Snurr, R. Q.; Hupp, J. T.; Yildirim, T.; Farha, O. K.; Mirkin, C. A. Chem. Mater. 2013, 25, 3539-3543.

(25) Lin, X.; Jia, J.; Zhao, X.; Thomas, K. M.; Blake, A. J.; Walker, G. S.; Champness, N. R.; Hubberstey, P.; Schröder, M. Angew. Chem., Int. Ed. 2006, 45, 7358-7364.

(26) Chen, B.; Ockwig, N. W.; Millward, A. R.; Contreras, D. S.; Yaghi, O. M. Angew. Chem., Int. Ed. 2005, 44, 4745-4749.

(27) Cambridge Structural Database searched using Conquest software.

(28) Hu, Y.; Xiang, S.; Zhang, W.; Zhang, Z.; Wang, L.; Bai, J.; Chen, B. Chem. Commun. 2009, 7551-7553.

(29) Lee, Y.-G.; Moon, H. R.; Cheon, Y. E.; Suh, M. P. Angew. Chem., Int. Ed. 2008, 47, 7741-7745.
(30) Prasad, T. K.; Hong, D. H.; Suh, M. P. Chem.-Eur. J. 2010, 16, 14043-14050.

(31) Wang, X.-S.; Ma, S.; Rauch, K.; Simmons, J. M.; Yuan, D.; Wang, X.; Yildirim, T.; Cole, W. C.; López, J. J.; de Meijere, A.; Zhou, H.-C. Chem. Mater. 2008, 20, 3145-3152.

(32) Xue, M.; Zhu, G.; Li, X.; Zhao, X.; Jin, Z.; Kang, E.; Qiu, S. Cryst. Growth Des. 2008, 8, 2478-2483.

(33) Yang, S.; Lin, X.; Dailly, A.; Blake, A. J.; Hubberstey, P.; Champness, N. R; Schroder, M. Chem.—Eur. J. 2009, 15, 4829-4835.

(34) Zhao, D.; Yuan, D.; Yakovenko, A.; Zhou, H.-C. Chem. Commun. 2010, 46, 4196-4198.

(35) Zheng, B.; Liang, Z.; Li, G.; Huo, Q.; Liu, Y. Cryst. Growth Des. 2010, 10, 3405-3409.

(36) Wang, X.-S.; Meng, L.; Cheng, Q.; Kim, C.; Wojtas, L.; Chrzanowski, M.; Chen, Y.-S.; Zhang, P. X.; Ma, S. J. Am. Chem. Soc. 2011, 133, 16322-16325.

(37) Duan, X.; Yu, J.; Cai, J.; He, Y.; Wu, C.; Zhou, W.; Yildirim, T.; Zhang, Z.; Xiang, S.; O'Keeffe, M.; Chen, B.; Qian, G. Chem. Commun. 2013, 49, 2043-2045.

(38) Farha, O. K.; Spokoyny, A. M.; Mulfort, K. L.; Galli, S.; Hupp, J. T.; Mirkin, C. A. Small 2009, 5, 1727-1731.

(39) Farha, O. K.; Spokoyny, A. M.; Mulfort, K. L.; Hawthorne, M. F.; Mirkin, C. A.; Hupp, J. T. J. Am. Chem. Soc. 2007, 129, 1268012681.

(40) Spokoyny, A. M.; Farha, O. K.; Mulfort, K. L.; Hupp, J. T.; Mirkin, C. A. Inorg. Chim. Acta 2010, 364, 266-271.

(41) Safronov, A. V.; Sevryugina, Y. V.; Jalisatgi, S. S.; Kennedy, R. D.; Barnes, C. L.; Hawthorne, M. F. Inorg. Chem. 2012, 51, 26292637.

(42) Hawthorne, M. F.; Young, D. C.; Andrews, T. D.; Howe, D. V.; Pilling, R. L.; Pitts, A. D.; Reintjes, M.; Warren, L. F.; Wegner, P. A. J. Am. Chem. Soc. 1968, 90, 879-896.

(43) Warren, L. F.; Hawthorne, M. F. J. Am. Chem. Soc. 1970, 92, 1157-1173.

(44) Finze, M. Inorg. Chem. 2008, 47, 11857-11867.

(45) Yoo, J.; Hwang, J.-W.; Do, Y. Inorg. Chem. 2001, 40, 568-570.

(46) In previously reported anionic indium-based frameworks, the hydrolysis of the dimethylamide solvent under the acidic solvothermal conditions leads to the formation of dimethylammonium $\left[\mathrm{Me}_{2} \mathrm{NH}_{2}\right]^{+}$ cations, which often persist in the crystal structure. For an example, see: Yang, S.; Lin, X.; Lewis, W.; Suyetin, M.; Bichoutskaia, E.; Parker, J. E.; Tang, C. C.; Allan, D. R.; Rizkallah, P. J.; Hubberstey, P.; Champness, N. R.; Thomas, K. M.; Blake, A. J.; Schröder, M. Nature Mater. 2012, 11, 710-716 In the cases of the crystal structures reported in the present paper, it was not possible to locate either the original $\left[\mathrm{PPh}_{4}\right]^{+}$cation or solvothermally derived $\left[\mathrm{Me}_{2} \mathrm{NH}_{2}\right]^{+}$within the pores of the framework..

(47) The solvent masking procedure as implemented in Olex2 was used to remove the electronic contribution of disordered and illdefined solvent molecules or couter cations from the refinement: Dolomanov, O. V.; Bourhis, L. J.; Gildea, R. J.; Howard, J. A. K.; Puschmann, H. J. Appl. Crystallogr. 2009, 42, 339-341.

(48) Spek, A. L. PLATON (C), 1980-2011; Padualaan 8, 3584 CH, Utrecht, The Netherlands. The van der Waals radii used in the analysis C:1.70, H:1.2, B:1.63, Cu:1.4, N:1.5,O:1.52.

(49) The 4-c net has the symbol ssb.

(50) Eddaoudi, M.; Kim, J.; Wachter, J. B.; Chae, H. K.; O'Keeffe, M.; Yaghi, O. M. J. Am. Chem. Soc. 2001, 123, 4368-4369.

(51) Moulton, B.; Lu, J.; Mondal, A.; Zaworotko, M. J. Chem. Commun. 2001, 863-864.

(52) Clingerman, D. J.; Kennedy, R. D.; Mondloch, J. E.; Sarjeant, A. A.; Hupp, J. T.; Farha, O. K.; Mirkin, C. A. Chem. Commun. 2013, $11485-11487$.

(53) Farha, O. K.; Eryazici, I.; Jeong, N. C.; Hauser, B. G.; Wilmer, C. E.; Sarjeant, A. A.; Snurr, R. Q.; Nguyen, S. T.; Yazaydın, A. Ö.; Hupp, J. T. J. Am. Chem. Soc. 2012, 134, 15016-15021.

(54) Farha, O. K.; Wilmer, C. E.; Eryazici, I.; Hauser, B. G.; Parilla, P. A.; O’Neill, K.; Sarjeant, A. A.; Nguyen, S. T.; Snurr, R. Q.; Hupp, J. T. J. Am. Chem. Soc. 2012, 134, 9860-9863. 
(55) Zou, Y.; Park, M.; Hong, S.; Lah, M. S. Chem. Commun. 2008, 2340-2342.

(56) Yuan, D.; Zhao, D.; Sun, D.; Zhou, H.-C. Angew. Chem., Int. Ed. 2010, 49, 5357-5361.

(57) Perry, J. J., IV; Perman, J. A.; Zaworotko, M. J. Chem. Soc. Rev. 2009, 38, 1400-1417.

(58) Wang, X.-S.; Ma, S.; Forster, P. M.; Yuan, D.; Eckert, J.; López, J. J.; Murphy, B. J.; Parise, J. B.; Zhou, H.-C. Angew. Chem., Int. Ed. 2008, 47, 7263-7266.

(59) Hu, Y. -X.; Ma, H. -B.; Zhang, W. -W.; Xiang, S.; Zhai, L.; Wang, L. -F.; Chen, B.; Ren, X. -M.; Bai, J. Inorg. Chem. 2012, 51, 7066-7074. (60) Li, M.; Li, D.; O’Keeffe, M.; Yaghi, O. M. Chem. Rev. 2014, 114, $1343-1370$. 